\title{
Rock Strength and Geometallurgical Modelling, Mogalakwena Mine
}

\author{
by J. P. Germiquet** and R.C.A. Minnitt ${ }^{\dagger}$
}

\section{Synopsis}

Rock properties have a material impact on mining processes, including drilling performance. An investigation using point loaded index (PLI) data converted to uniaxial compressive strength (UCS) has revealed that a direct relationship between grain size and UCS exists at Mogalakwena Mine. This correlation is best seen in unaltered rock, with lower correlations for altered rock types. Measurements from the new RockMa system installed on drill rigs can be used to obtain rock strength data to validate the current rock strength domains and create additional data for the next benches below. An investigation of penetration rates in different lithologies shows that rock composition plays an important role in determining drill performance. Additionally, there is an inverse relationship between rock strength and drilling penetration rate - a measure of how efficiently a hole is drilled.

The domaining of grain-size-adjusted UCS at Mogalakwena Mine will allow more accurate scheduling of drill rigs through increased knowledge of rock strength in various areas. Successful rock strength domaining has the potential to be incorporated into blast indexing and predicting crushing/milling performance.

\section{Keywords}

geometallurgy, rock strength, point load, comminution, drilling rate of penetration, crushing.
Overysel (OY) exploration database for the study. Point load testing was done for each borehole and the results converted to uniaxial compressive strength (UCS) (Akram and Bakar, 2007). The relationship of lithology, texture, and grain size with UCS revealed an inverse relationship between grain size and UCS in unaltered rock. The relationship was not present in altered rock types. A comparison of mean strength and hardness results indicated that Bond work index and UCS may be related. Drilling performance is affected by UCS (Bourgoyne et al., 1986), and this was proven using recent measurements obtained during drilling. Lastly, grain-sizeadjusted UCS values were applied to a 3D model for the OY property.

\section{The case for understanding rock properties}

Rock properties have a material impact on mining processes, including slope design, drilling, blasting comminution, and flotation. An investigation into penetration rates in different lithologies will show that rock properties play an important role in determining drill performance. There is an inverse relationship between rock strength and drilling penetration rate - a measure of how efficiently a blast-hole is drilled (Bourgoyne et al., 1986). UCS is used widely in the mining industry to quantify rock strength. An investigation using point load index (PLI) data converted to UCS has revealed a direct relationship between grain size and UCS at Mogalakwena. This correlation is best seen in

\footnotetext{
* Geology Department, Mogalakwena Mine, South Africa.

$\dagger$ University of the Witwatersrand.

(C) The Southern African Institute of Mining and Metallurgy, 2016. ISSN 2225-6253. This paper was first presented at the, 23rd International Symposium on Mine Planning and Equipment Selection (MPES) 2015, 8-11 November 2015, Sandton Convention Centre, Johannesburg, South Africa.
} 


\section{Rock Strength and Geometallurgical Modelling, Mogalakwena Mine}

unaltered rock, with lower correlations for altered rock types. Drilling data from the newly installed RockMa system on drill rigs can be used to obtain rock strength data to validate the current rock strength models and create additional data for benches below. The domaining of grain-size-adjusted UCS at Mogalakwena Mine will allow for more accurate drill rig scheduling and blast indexing, and open up the potential for predicting the comminution characteristics of ore batches.

\section{Lithological and textural investigation}

Data from 754 exploration boreholes located on the OY property shows that 97 rock types and 34 textural descriptions are used in the Mogalakwena database. Although complexity of the nomenclature allows for greater naming accuracy, it reduces both standardization and usefulness while inadvertently encouraging subjectivity. The analysis revealed that only seven rock types and four textural descriptions are sufficient to represent $97 \%$ of the coded lithological entries for the reef stratigraphy (Figures 1 and 2).

The major reef lithology is feldspathic pyroxenite, which conforms with studies done at other farms within the Mogalakwena Mine property (Hayes and Piper, 2003) (Figure 1). Feldspathic pyroxenite and pyroxenite comprise $80 \%$ of the lithological entries in the database. Entries reveal the less frequent occurrence of serpentinization of the reef at OY compared to the Zwartfontein and Sandsloot farms.
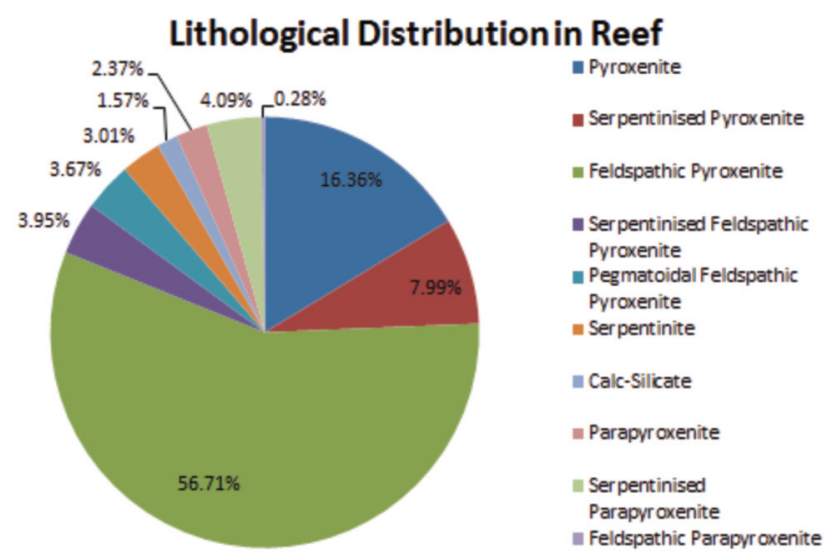

Figure 1-Lithological descriptions used for reef stratigraphic unit

\section{Reef Textural Distribution}

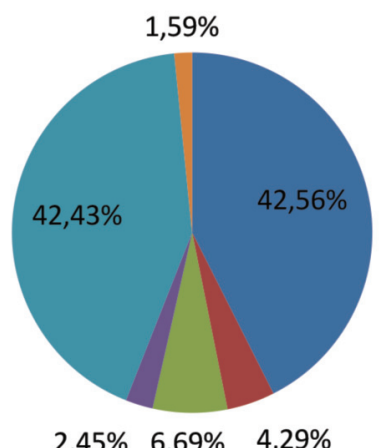

- CUMU

-PEG

- RECRY

- VARI

Elank

ather

Figure 2-Textural descriptions used in the reef stratigraphic unit for cumulus (CUMU), pegmatitic (PEG), recrystallized (RECRY), and varied (VARI) units
Texturally, the unaltered reef lithologies (feldspathic pyroxenite and pyroxenite) are dominated by a cumulate textures, while altered reef lithologies are dominated by a recrystallized texture (Figure 2 ).

\section{Relationship between rock strength and texture}

A number of compositional and textural factors influence rock strength. Grain size specifically has a significant influence on rock strength (Akram and Bakar, 2007). Generally, rock strength ranges at Mogalakwena Mine would be classified as high to very high, and fall within a rather narrow range. The relationship between grain size and UCS for various rock types is depicted in Figure 3.

The results show that rock composition and mineral content influence the range of UCS for specific rock types. Feldspathic pyroxenite (FPYX) has a higher feldspar content than pyroxenite (PYX), resulting in a higher mean UCS. The curves in Figure 3 indicate an inverse relationship between grain size and rock strength for unaltered rocks. This relationship was confirmed with a set of 41 feldspathic pyroxenite samples from exploration core. The variability in UCS between rock types shows that major rock types differ sufficiently in mean UCS to allow for rudimentary geometallurgical rock strength characterization.

\section{Correlation between rock strength and hardness}

Expanding the research into the relationship between rock strength and comminution-specific tests would strengthen the use of in-situ strength parameters in process optimization. Studies conclude that there is a fair correlation between UCS and drop weight test (DWT) values, which allows for the use of UCS as a proxy for crushing efficiency (Bye, 2005). Multiple studies confirm little or no correlation between UCS and Bond Work index (BWi) values, indicating that UCS cannot be used as an indirect proxy for milling performance. BWi is an industry-accepted test to describe milling behaviour (Doll, Barrat, and Wood, 2003). Average values of UCS and BWi for rock samples taken at Mogalakwena confirm some correlation (Figure 4).

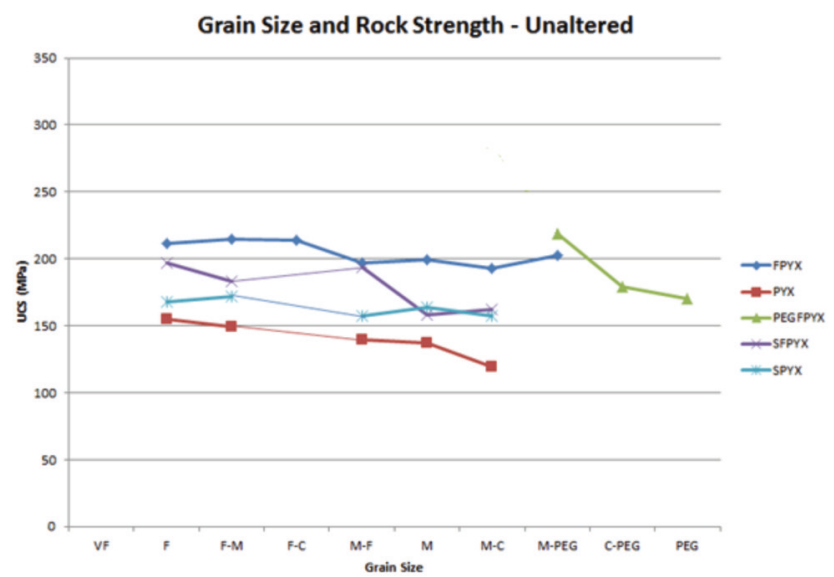

Figure 3-Inverse correlation between rock strength and grain size. Rock nomenclature is as follows: feldspathic pyroxenite (FPYX), pyroxenite (PYX), pegmatoidal feldspathic pyroxenite (PEGFPYX) 


\section{Rock Strength and Geometallurgical Modelling, Mogalakwena Mine}

\section{Drilling penetration rates and rock strength}

The penetration rate of production drill rigs is affected by rock strength (Bourgoyne et al., 1986). A comparison of rock strength and penetration rate shows an inverse relationship between penetration rate and rock strength. Mafic-rich reef material (pyroxenite in particular) has the highest penetration rate, with hangingwall and footwall rocks showing slower rates (Figure 5). More accurate scheduling of drilling rigs can be achieved by utilizing accurate penetration rates for different rock types or stratigraphic units.

\section{Measurements while drilling (MWD)}

MWD technology has enhanced the ability to measure drilling performance variables. The results are calculated using the performance variables (but are not calibrated at time of writing). Currently, qualitative rock strength measurements gathered by the RockMa drilling system displays rock strength colour signatures revealing different strengths in different stratigraphic units. The data can be loaded for an entire bench to show strength changes along strike and dip of the orebody. The system was applied to Cut 8 at Mogalakwena, where the hangingwall norite on bench 8 was unaltered, while the reef and footwall were more weathered

\section{BWI vs UCS}

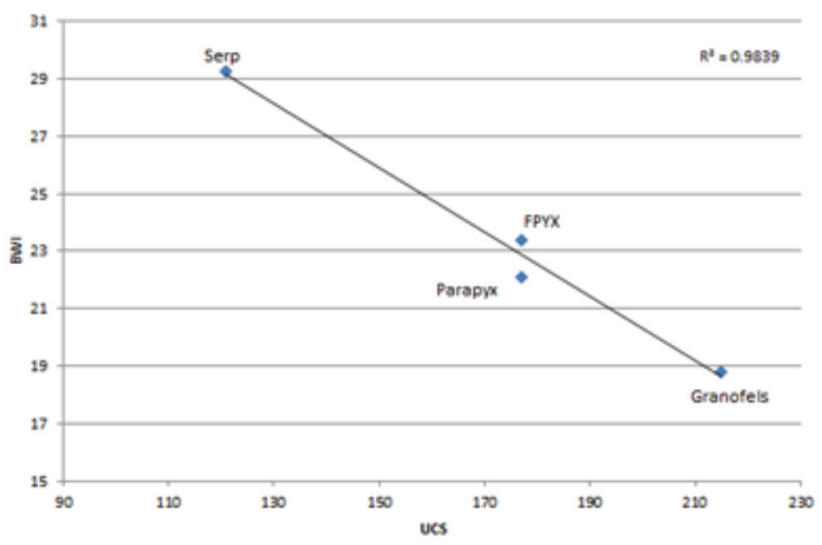

Figure 4-Mean BWi plotted against UCS for major rock types

Penetration Rate vs Exploration UCSRock Types from Chip Logging

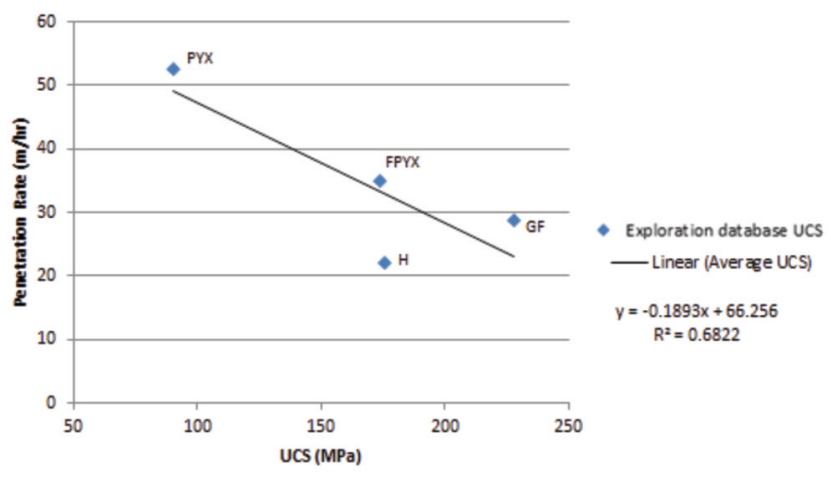

Figure 5-Penetration rate compared to UCS for four rock types. Rock nomenclature is as follows: pyroxenite (PYX), feldspathic pyroxenite (FPYX), granofels (GF), and hybrid norite (H) and oxidized (Figure 6). Plotted blue holes indicate stronger rock than the yellow holes. The area between the blue and red lines is the estimated position of the oxidized reef.

The qualitative data can be used to identify the different stratigraphic units and localized changes in reef strike, which may not be known prior to production drilling. This rock strength information can be calibrated and used to update a UCS model for patterns before blasting.

\section{Rock strength modelling}

A geometallurgical model requires accurate sampling of ore variables (Deutch, 2013). Rock strength is one such variable. Usually, rock strength modelling is based on a calculated average for the rock type which disregards textural differences (Hayes and Piper, 2003). Textual changes were incorporated into the data-set to represent more accurate rock strength changes across the orebody (Figure 7).

The model can be updated at smaller grid spacing using strength data generated by calibrated MWD technology. Potentially, mining blocks can be delineated within the model for predicting and simulating drilling, blasting, crushing, or milling performance. Predictive tools are vital for the optimization of mining and plant processes.

\section{Financial benefits}

The South Plant concentrator at Mogalakwena Mine utilizes autogenous milling, which is heavily dependent on two populations of feed material - coarse (strong) and fine (weak) material. The two feed material types are separated after primary crushing by means of a grizzly and stockpiled

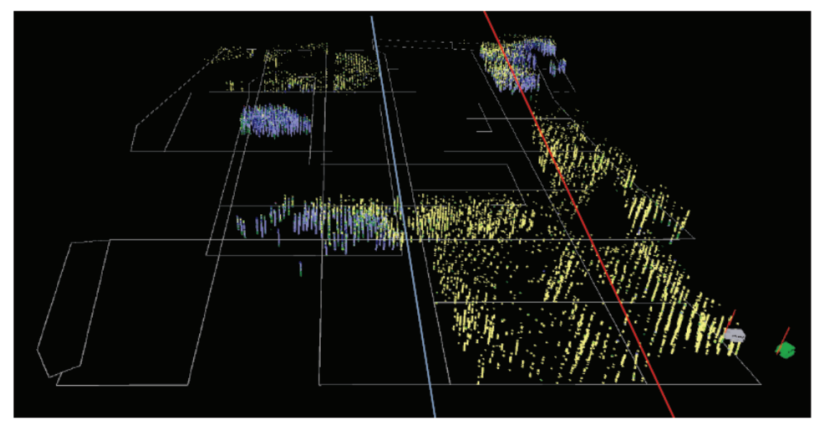

Figure 6-Qualitative rock strength data displayed in the RockMa software package for Cut 8

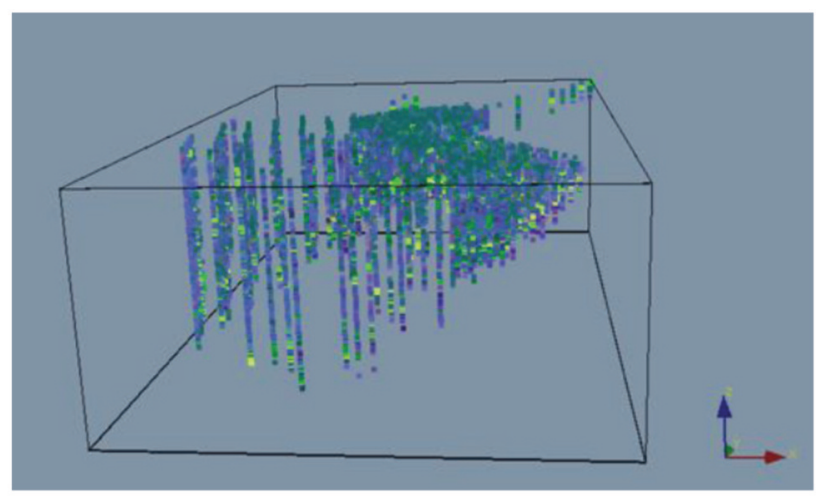

Figure 7-Rock strength domaining using grain-size-adjusted UCS 


\section{Rock Strength and Geometallurgical Modelling, Mogalakwena Mine}

separately. The plant has suffered from stoppages related to the depletion of the coarse material, resulting in a total of 226.02 hours of lost milling in 2014. At an average milling rate of $380.74 \mathrm{t} / \mathrm{h}$, the lost output is over $86 \mathrm{kt}$ for 2014 . Had the stoppages been avoided, total output for 2014 from South Plant would have increased by $2.58 \%$. At mean PGE grades, recoveries, and commodity prices, the lost revenue amounts to R51.35 million.

The findings show that in-situ ore strength characterization would allow a stable feed supply, based on the required rock strength proportions in the feed to South Plant. Two additional stockpiles based on rock strength would stabilize the ore feed to the requirements of South Plant (Figure 9).

\section{Discussion}

The performance of mining and plant equipment is directly affected by rock properties. Simplified, fit-for-purpose lithological and textural nomenclature allows for useful rock type descriptions in a large-scale opencast mining environment. Lithological and textural descriptions will need to be suited for each pit area in order to represent changes in reef character between farms (such as lower occurrence of altered ores). Additionally, the research shows that identifying pyroxenite and feldspathic pyroxenite within the

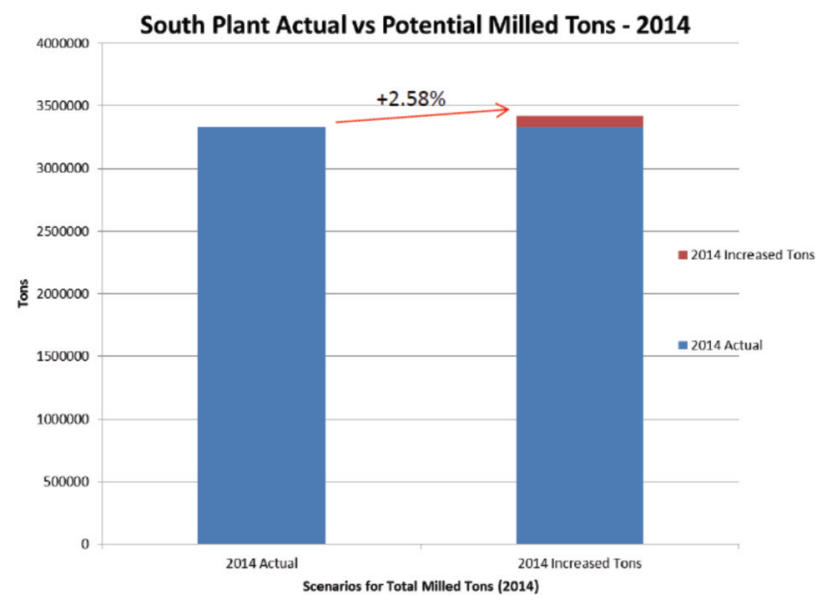

Figure 8-Actual milled tons vs. potential milled tons without stoppages

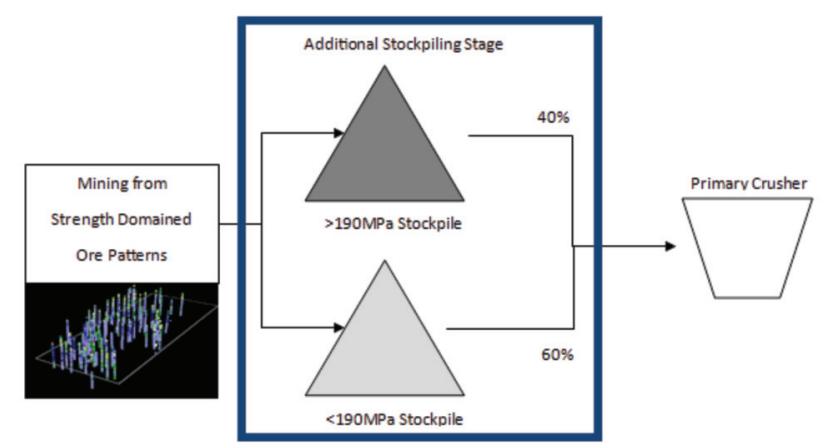

Figure 9-Additional stockpiling stage before primary crushing to stabilize grade and rock strength reef would categorize $80 \%$ of the ore. Focusing efforts on characterizing strength changes within these two lithological units would be more beneficial for modelling. The differences in strength of the two rock types alone would indicate probable differences in plant response. Rock strength values obtained through cost-efficient point load testing are inversely correlated withgrain size. This realization allows for more accurate rock strength domaining and modelling. Accurate modelling will also be useful for scheduling drill rigs and averting extended standing times. Mineralogical or geochemical variables can be added to fine-tune the understanding of rock strength and rock type for more advanced geometallurgical modelling. Ultimately, rock strength and hardness domaining will guide plant feed, with a positive effect on plant throughput as shown by the potential financial benefits at South Plant.

\section{Conclusion}

The research established a source of relevant data for a geometallurgical programme, which includes rock strength variability based on rock type. Rock strength has a material effect on drilling performance and scheduling can be optimized. The project revealed that ore categories can be tailored to represent variables that impact mining performance, including the potential to predict plant performance. The results increase understanding of geometallurgical variability in day-to-day mining operations, enabling optimization of the downstream recovery process.

\section{References}

Akram, M. and Bakar, Z.A. 2007. Correlation between uniaxial compressive strength and point load index for salt-range rocks. Pakistan Journal of Engineering and Applied Science, vol. 1.

http://www.uet.edu.pk/research/researchinfo/journal/volume1/article1.pdf

Bourgoyne, A.T., Milheim, K.K., Chenevert, M.E., and Young, F.S. 1986. Applied Drilling Engineering. 2nd edn. Society of Petroleum Engineers, Richardson, TX.

Bye, A. 2005. Geotechnical, metallurgical and blasting information for blast 138-055. Anglo American Platinum, internal report.

Deutch, C.V. 2013. Geostatistical modelling of geometallurgical variables problems and solution. Proceedings of GEOMET 2013: the Second AUSIMM International Geometallurgy Conference, Perth, Western Australia, 30 September -2 October.Australasian Institute of Mining and Metallurgy, Melbourne. pp. 7-16.

Doll, A.D., Barrat, D.J., and Wood, K. 2003. Comparison of UCS to Bond Work Indices. Alex G Doll Consulting Ltd, Edmonton, Canada. https://www.sagmilling.com/articles/9/view/?s=1

Hayes, S. and Piper, P.S. 2003. Point load tests on various rock types at Potgietersrus Platinum Mine for determination of rock strength. Groundwork Consulting (Pty) Ltd, Johannesburg.

Nex, P., Kinnaird, J., Jones, B., and Colloty, A. 2006. Platreef rock type definitions and descriptions. Anglo American Platinum.

Ozturk, C.A., Nasuf, E., and Kahraman, S. 2014. Estimation of rock strength from quantitative assessment of rock texture. Journal of the Southern African Institute of Mining and Metallurgy, vol. 114, no. 6. pp.471-80. 